Research Article

\title{
Effect of positive end-expiratory pressure value on change in end- tidal carbon dioxide as a predictor of fluid responsiveness in Patients Undergoing Passive Leg Raising Maneuver
}

\author{
Lutfi Nur Farid $^{1 *}$, Hardiono ${ }^{2}$, Pesta Parulian Maurid Edwar ${ }^{3}$ \\ 1) Resident of Department/SMF of Anesthesiology and Intensive Therapy, Faculty of Medicine, Universitas \\ Airlangga - RSUD Dr. Soetomo Surabaya \\ 2,3) Staff of Department/SMF of Anesthesiology and Intensive Therapy, Faculty of Medicine, Universitas \\ Airlangga - RSUD Dr. Soetomo Surabaya
}

\begin{tabular}{ll} 
A R T I C L E & I N F O \\
\hline Submitted & $: 18^{\text {st }}$ July 2020 \\
Accepted & $: 03^{\text {st }}$ February 2021 \\
Published & $: 25^{\text {st }}$ July 2021
\end{tabular}

Keywords:

change in end tidal carbon dioxide, fluid responsiveness, positive endexpiratory pressure, passive leg raising, cardiac output surrogate

\section{*Correspondence:}

lutfithe13th@gmail.com

This is an Open acces article under the CC-BY-NC license

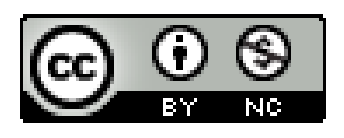

\begin{abstract}
Identification of patients' fluid status in the emergency room should be made before giving fluid therapy. This study aimed to determine the effect of positive end-expiratory pressure on change in end-tidal carbon dioxide during passive leg raising maneuver to predict fluid responsiveness. Thirty subjects aged $18-65$ years in the resuscitation room, all on the ventilator, were divided into three groups according to their positive end-expiratory pressure value: low (0-5 cmH2O), moderate (6-10 $\mathrm{cmH} 2 \mathrm{O})$, and high (>10 $\mathrm{cmH} 2 \mathrm{O})$. Every subject underwent passive leg raising to simulate fluid administration. Values of blood pressure, heart rate, cardiac output, and end-tidal carbon dioxide were recorded before and after the maneuver. Analysis of the three groups found a significant correlation between change in end-tidal carbon dioxide with a cut-off value of $5 \%$ and $1 \mathrm{mmHg}$ with fluid responsiveness of subjects in the low $(p=0.028)$ and moderate $(p=0.013)$ but not in the high positive end-expiratory pressure group $(p=0.333)$. In conclusion, change in end-tidal carbon dioxide in mechanically ventilated patients undergoing passive leg raising maneuvers can be used as a predictor of fluid responsiveness, but this method cannot be used on patients with high positive end-expiratory pressure $(>$ $10 \mathrm{cmH} 2 \mathrm{O}$ ).
\end{abstract}




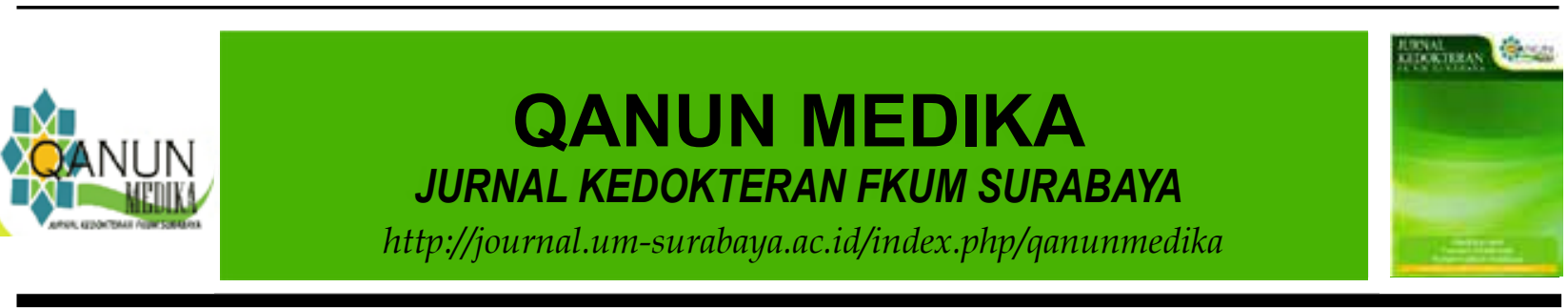

\section{INTRODUCTION}

Almost half of the critically ill patients with unstable hemodynamic is not fluid responsive; for those patients, resuscitation with fluid bolus is dangerous. It can cause complications like iatrogenic saltwater drowning, Severe Acute Respiratory Distress Syndrome, Acute Kidney Injury, and death (Marik, Cavallazzi, Vasu, \& Hirani, 2009; Schuller \& Schuster, 2006). Researches to find a parameter to predict patients' fluid responsiveness has been done, classically with static parameters such as central venous pressure (CVP), pulmonary artery occlusion pressure (PAOP), left ventricular end-diastolic area (LVEDA), inferior vena cava (IVC) diameter, and intrathoracic blood volume index (ITBVI). That static parameter has its limit that they only predict preload value. Nonetheless, every heart works in the different part of FrankStarling curve, so does every preload value. We can't directly predict the effect of preload increase on stroke volume or cardiac output (Zochios \& Wilkinson, 2011).

Most dynamic parameters to predict fluid responsiveness are based on heart-lung interaction. The physiologic basis is the cyclic change of right and left ventricle preload caused by positive pressure ventilation. The bigger the change, the bigger the chance that the patient is fluid responsive. Pulse pressure variation, stroke volume variation, IVC distensibility index, and more recently, internal jugular vein variability have been studied, satisfying sensitivity and specificity, but they still share the same weakness. Arrhythmia, spontaneous respiration, low tidal volume or high-frequency ventilation, and low lung compliance have been found to decrease their accuracy (Michard, Chemla, \& Teboul, 2015; Monnet et al., 2012).

A recent study in fluid responsiveness shows good performance of old but new methods known as passive leg raising. The principle of this maneuver is moving vein blood from the lower extremity to systemic circulation by raising patients' legs by 45 degrees. During the maneuver, change in cardiac output is monitored with echocardiography, esophageal Doppler, or arterial pulse contour analysis. An increase of more than $10 \%$ in cardiac output or stroke volume is considered as a positive result for fluid responsiveness. Its physiological basis is like a fluid challenge, but in PLR, the increase in intravascular volume is caused by autotransfusion that is reversible. Those maneuvers differ from fluid bolus in the fluid challenge that uses external fluid administration and increases total intravascular volume permanently (Monnet et al., 2012; Monnet \& Teboul, 2015). One study found from echocardiography and radial artery pulse pressure that the hemodynamic effect of PLR is equal to $300 \mathrm{~mL}$ fluid administration in 20 minutes (Boulain et al., 2002). The increase in venous return will increase right ventricle preload, right ventricle cardiac output, followed by an increase in left ventricle cardiac output. The effect of passive leg raising to heart preload will diminish when the legs are back in horizontal position, so PLR can be considered a short, safe, and reversible volume challenge (Monnet et al., 2012).

Continuous cardiac output monitoring during PLR needs relatively expensive and sophisticated devices and operators' expertise. There is a need to find simple bedside cardiac output surrogate. Carbon dioxide is produced in the body due to aerobic metabolism, diffused to blood and brought to the lung, then diffused back to alveoli. Carbon dioxide in gas form then goes through the bronchus and upper airway and can be detected in exhaled breath as end-tidal carbon dioxide with capnography (Ortega, Connor, Kim, Djang, \& Patel, 2012). Studies found that end-tidal carbon dioxide can be used to measure cardiac output change in situations like low cardiac output or massive 
bleeding (Jin et al., 2000; Weil, Bisera, Trevino, \& Rackow, 1985). The underlying mechanism is that $\mathrm{EtCO} 2$ is determined by three factors: carbon dioxide produced by aerobic metabolism in cell, pulmonary blood flow (in no shunt condition equal to cardiac output) that bring carbon dioxide from peripheral tissue to lung, and lung ability to diffuse $\mathrm{CO} 2$ out to alveoli as minute ventilation. If two of three factors don't change in a short time, then a change in $\mathrm{EtCO} 2$ will represent the change in the third factor (Basappanavar et al., 2018; Pantazopoulos et al., 2015).

Some studies have evaluated the ability of the change in $\mathrm{EtCO} 2$ as cardiac output surrogate during the fluid challenge or PLR maneuver. Monnet et al. found that change in $\mathrm{EtCO} 2$ during PLR with a cut-off value of $5 \%$ can predict fluid responsiveness with a sensitivity of $71 \%$ and specificity of $100 \%$, better than pulse pressure variation (Monnet et al., 2013). Another study in France that compares several predictor for fluid responsiveness such as change in heart rate, pulse pressure, systolic blood pressure, femoral blood flow, and pulse pressure variation, and EtCO2 in ICU patients with mechanical ventilation and clinical signs of shock found that change in EtCO2 more than $1 \mathrm{mmHg}$ during volume expansion with 500 $\mathrm{mL}$ crystalloid is the strongest predictor of fluid responsiveness (Lakhal et al., 2017). A study in China in patients with septic shock found that change in $\mathrm{EtCO} 2$ greater than or equal to $5 \%$ during PLR may predict fluid responsiveness with $75.8 \%$ sensitivity and $93.4 \%$ specificity (Xiao-Ting et al., 2015). These studies gave hope, but as its finding is still relatively new, no study has been made specifically to find its limitation yet.

Positive end-expiratory pressure (PEEP) is part of positive pressure ventilation that improves recruitment and oxygenation. It has a positive effect on respiration but has a resultant negative effect on the circulation system. Heart-lung interaction happened because of their anatomic location, encased within the same rigid chest wall, and the lungs encompass the heart in the cardiac notch. The heart acts, therefore, as a pressure chamber within another pressure chamber. The surrounding pressure is not atmospheric in the thoracic cavity but the pleural pressure (PPL). Changes in PPL relative to atmospheric pressure over the respiratory cycle cyclically affect the gradient for venous return and preload and afterload. With mechanical ventilation, the application of PEEP, and the absence of spontaneous breathing efforts, PPL is positive throughout the respiratory cycle, with several physiological consequences: (i) elevated alveolar pressure (PAL) combined with the recumbent position alters pulmonary blood flow by creating lung areas with zone 1 conditions (compression of alveolar vessels) and increasing the proportion of areas with zone 2 conditions, causing increased pulmonary vascular resistance (PVR) and dead space ventilation with loss of functional residual capacity (FRC); (ii) increased intrathoracic pressure (ITP) reduced transmural pressure (PTM) of large intrathoracic blood vessels as venae cavae and thoracic aorta, thereby diminishing intrathoracic blood volume; (iii) ITP is transmitted to the pericardium in the cardiac fossa where the heart is trapped and exposed to pressure elevation. As right atrial pressure (RAP) is elevated with positive ITP, venous return goes down, thus cardiac output also goes down (Grübler Martin, Olivier, David, \& Stefan, 2017). Since higher PEEP equals higher ITP, it will also raise RAP. According to Frank-Starling curve, there will be a different increase in $\mathrm{CO}$ or $\mathrm{SV}$ for the same volume administration for different RAP baseline. We suspect PEEP can confound EtCO2 $(\triangle \mathrm{EtCO} 2)$ change to predict fluid change responsiveness in mechanically ventilated patients who underwent PLR maneuver to simulate fluid administration. 


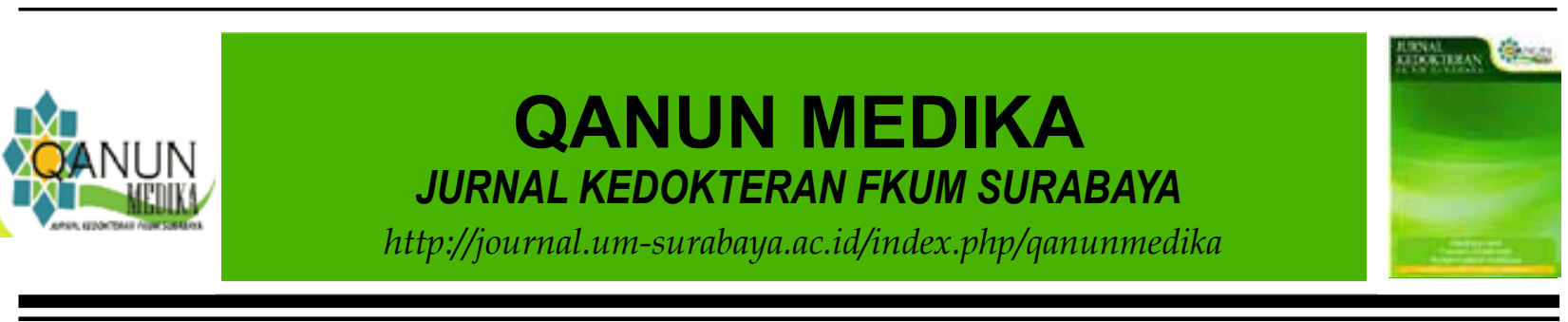

\section{METHODS}

This study design is observational analytic with prospective cohort study, with sampling method of consecutive sampling. This study has been ethically approved by Komite Etik Penelitian Kesehatan RSUD Dr. Soetomo Surabaya with ethical clearance certificate number 1799/KEPK/1/2020. The population of this study was critically ill patients with mechanical ventilation. The sample for this study was 30 adult patients with mechanical ventilation who were admitted to the resuscitation room of the Emergency Room of RSUD Dr. Soetomo Surabaya between January-February 2020 and met inclusion and exclusion criteria. The inclusion criteria of this study were: (i) Adult patients (18-65 years old) with mechanical ventilation; (ii) Not more than one hour since intubation performed; (iii) Not breathing spontaneously/still under relaxant, and (iv) With ventilator setting of tidal volume 6-8 $\mathrm{mL} / \mathrm{kg}$ predicted body weight (PBW). The exclusion criteria of this study were: (i) Patient had a contraindication for passive leg raising (wound, trauma in lower extremity or abdomen); (ii) Patient with suspected intraabdominal hypertension; (iii) Patient has a contraindication for echocardiography (wound, trauma); (iv) Patient with lung edema, traumatic brain injury, or suspected of increased intracranial pressure; (v) Patient wear compression stocking; and (vi) Patient whose family refused to be included in this study.

After the information to consent was explained and the family agreed to sign the informed consent, the patient was positioned at 45 degrees in a semi-recumbent position for five minutes before the PLR maneuver. Vital signs would be measured twice, before and during the PLR maneuver. Subjects were grouped according to their positive end-expiratory pressure ventilator parameter values into three groups: low (0-5 cmH2O), moderate (6-10
cmH2O), and high (> $10 \mathrm{cmH} 2 \mathrm{O})$. Heart rate (HR0), mean arterial pressure (MAP0), and ETCO2 (ET0) of the subject were recorded from the monitor, and echocardiography to obtain cardiac output ( $\mathrm{CO} 0)$ was performed. The patient's upper body was then lowered to horizontal, and his legs were raised at 45 degrees up, and cardiac output was then remeasured before 90 seconds. Heart rate (HR1), mean arterial pressure (MAP1), and ETCO2 during PLR (ET1) were then recorded from the monitor. The patient then reverted to the original position and monitored for possible side effects. If during PLR patients suffering from hemodynamic instability, desaturation, agitation, or sign of lung oedema, the maneuver stopped, subject reverted to original position and given treatment.

The collected data analyzed with SPSS 17.0 software. Fluid responsiveness was defined by increased of cardiac output by $10 \%$ or more during PLR. Statistical tests were performed to compare parameter values before and after passive leg raising, correlation of change in parameter value to change in cardiac output, and correlation of change in end-tidal carbon dioxide to fluid responsiveness in three groups of subjects. The significance level is 0.05 , and the confidence interval is $95 \%$.

\section{RESULTS}

Thirty patients who became the subject of this study consisted of 18 males $(60 \%)$ and 12 females $(40 \%)$. The mean age is $47.33 \pm$ 11.28 years, with a median of 51.5 years old. The characteristic of the subjects was described in Table 1. The most frequent diagnosis is pneumonia, followed by septic shock, tuberculosis, alcohol intoxication, and others (lung carcinoma, lung contusion, Guillain barre syndrome, asthma, and ketoacidosis diabetes). Nine subjects (30\%) used low PEEP (0-5 cmH2O), eighteen subjects $(60 \%)$ used moderate PEEP (6-10 cmH2O), and three From 


\section{QANUN MEDIKA \\ JURNAL KEDOKTERAN FKUM SURABAYA \\ http://journal.um-surabaya.ac.id/index.php/qanunmedika}

subjects (10\%) used high PEEP (>10 cmH2O).

No adverse event that prompted the PLR

maneuver to stop happened.

Table 1. Characteristic of the subject

\begin{tabular}{lll}
\hline Parameter & Variable & $\mathbf{n}(\mathbf{\%})$ \\
\hline Sex & Male & $18(60)$ \\
& Female & $12(40)$ \\
& $18-21$ y.o. & $1(3.3)$ \\
& $22-31$ y.o. & $3(10)$ \\
Age & $32-41$ y.o. & $5(16.7)$ \\
& $42-51$ y.o. & $6(20)$ \\
& $52-61$ y.o. & $13(43.3)$ \\
& $62-65$ y.o. & $2(6.7)$ \\
Height & $<140 \mathrm{~cm}$ & - \\
& $141-150 \mathrm{~cm}$ & $4(13.3)$ \\
& $151-160 \mathrm{~cm}$ & $16(53.3)$ \\
& $161-170$ & $10(30)$ \\
& $>170 \mathrm{~cm}$ & $1(3.3)$ \\
Diagnosis & Pneumonia & $11(33.3)$ \\
& Septic shock & $5(16.7)$ \\
& Tuberculosis & $5(16.7)$ \\
& Alcohol intoxication & $3(10)$ \\
& Others & $6(20)$ \\
\hline
\end{tabular}

Table 2. Comparison between parameters before and after PLR in fluid responder group and non fluid responder group.

\begin{tabular}{lcccccc}
\hline \multicolumn{1}{c}{ Parameter } & \multicolumn{2}{c}{ Fluid responder } & \multicolumn{4}{c}{ Non fluid responder } \\
& $\begin{array}{c}\text { Before } \\
\text { PLR }\end{array}$ & $\begin{array}{c}\text { During } \\
\text { PLR }\end{array}$ & $\mathbf{p}$ & $\begin{array}{c}\text { Before } \\
\text { PLR }\end{array}$ & $\begin{array}{c}\text { During } \\
\text { PLR }\end{array}$ & p \\
\hline $\mathrm{MAP}(\mathrm{mmHg})$ & $87 \pm 7.2$ & $88.4 \pm 6.5$ & 0.242 & $90.1 \pm 11.8$ & $91 \pm 9.7$ & 0.251 \\
$\mathrm{HR}(\mathrm{bpm})$ & $89.4 \pm 10.2$ & $90.4 \pm 9.9$ & 0.416 & $94.7 \pm 12.2$ & $96 \pm 10.6$ & 0.115 \\
$\mathrm{EtCO}$ & $32.9 \pm 2.1$ & $35.4 \pm 2.1^{\#}$ & $<.001$ & $32.2 \pm 1.8$ & $33.3 \pm 1.8^{\#}$ & $<.001$ \\
$(\mathrm{mmHg})$ & & & & & & \\
$\mathrm{CO}(\mathrm{L} /$ minute $)$ & $4.1 \pm 0.3$ & $4.7 \pm 0.2^{\#}$ & $<.001$ & $4.7 \pm 0.5$ & $4.9 \pm 0.5^{\#}$ & $<.001$ \\
\hline
\end{tabular}

\# Paired sample t-test compared to parameter before PLR with significant $\mathrm{p}$ value $<0.05$ 


\section{QANUN MEDIKA \\ JURNAL KEDOKTERAN FKUM SURABAYA}

http://journal.um-surabaya.ac.id/index.php/qanunmedika

Table 3. Chi-square test between two $\Delta \mathrm{EtCO}_{2}$ cut off value ability to predict fluid responsiveness of the subject.

\begin{tabular}{|c|c|c|c|c|}
\hline \multirow{2}{*}{$\begin{array}{c}\Delta \mathrm{EtCO}_{2} \text { cut } \\
\text { off value }\end{array}$} & \multirow{2}{*}{$\Delta \mathrm{EtCO}_{2}$ value } & \multicolumn{2}{|c|}{ Fluid Responsive? } & \multirow{2}{*}{$\mathbf{p}$} \\
\hline & & Yes $(n, \%)$ & No $(n, \%)$ & \\
\hline \multirow{2}{*}{$5 \%$} & $\leq 5 \%$ & $0(0 \%)$ & $17(100 \%)$ & \multirow{2}{*}{$<.001^{\#}$} \\
\hline & $>5 \%$ & $9(69.2 \%)$ & $4(30.8 \%)$ & \\
\hline \multirow{2}{*}{$1 \mathrm{mmHg}$} & $\leq 1 \mathrm{mmHg}$ & $0(0 \%)$ & $17(100 \%)$ & \multirow{2}{*}{$<.001^{\#}$} \\
\hline & $>1 \mathrm{mmHg}$ & $9(69.2 \%)$ & $4(30.8 \%)$ & \\
\hline
\end{tabular}

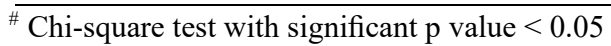

Table 4. Chi square test between two $\triangle \mathrm{EtCO}_{2}$ cut off value ability to predict fluid responsiveness of the subject, grouped according to their PEEP level.

\begin{tabular}{|c|c|c|c|c|c|}
\hline \multirow{2}{*}{$\begin{array}{c}\Delta \mathrm{EtCO}_{2} \text { cut } \\
\text { off value }\end{array}$} & \multirow{2}{*}{$\begin{array}{l}\text { PEEP } \\
\text { group }\end{array}$} & \multirow{2}{*}{$\begin{array}{c}\Delta \mathrm{EtCO}_{2} \\
\text { value }\end{array}$} & \multicolumn{2}{|c|}{ Fluid responsive? } & \multirow[b]{2}{*}{ p } \\
\hline & & & Yes $(n, \%)$ & No $(n, \%)$ & \\
\hline \multirow{6}{*}{$5 \%$} & \multirow{2}{*}{ Low } & $\leq 5 \%$ & $0(0 \%)$ & $7(100 \%)$ & \multirow{2}{*}{$0.028^{\#}$} \\
\hline & & $>5 \%$ & $2(100 \%)$ & $0(0 \%)$ & \\
\hline & \multirow{2}{*}{ Moderate } & $\leq 5 \%$ & $0(0 \%)$ & $8(100 \%)$ & \multirow{2}{*}{$0.013^{\#}$} \\
\hline & & $>5 \%$ & $6(60 \%)$ & $4(40 \%)$ & \\
\hline & \multirow{2}{*}{ High } & $\leq 5 \%$ & $0(0 \%)$ & $2(100 \%)$ & \multirow{2}{*}{0.333} \\
\hline & & $>5 \%$ & $1(100 \%)$ & $0(0 \%)$ & \\
\hline \multirow{6}{*}{$1 \mathrm{mmHg}$} & \multirow{2}{*}{ Low } & $\leq 1 \mathrm{mmHg}$ & $0(0 \%)$ & $7(100 \%)$ & \multirow{2}{*}{$0.028^{\#}$} \\
\hline & & $>1 \mathrm{mmHg}$ & $2(100 \%)$ & $0(0 \%)$ & \\
\hline & \multirow{2}{*}{ Moderate } & $\leq 1 \mathrm{mmHg}$ & $0(0 \%)$ & $8(100 \%)$ & \multirow{2}{*}{$0.013^{\#}$} \\
\hline & & $>1 \mathrm{mmHg}$ & $6(60 \%)$ & $4(40 \%)$ & \\
\hline & \multirow{2}{*}{ High } & $\leq 1 \mathrm{mmHg}$ & $0(0 \%)$ & $2(100 \%)$ & \multirow{2}{*}{0.333} \\
\hline & & $>1 \mathrm{mmHg}$ & $1(100 \%)$ & $0(0 \%)$ & \\
\hline
\end{tabular}

\footnotetext{
${ }^{*}$ Chi-square test with significant $\mathrm{p}$ value $<0.05$
} 
examination before PLR maneuver, mean $\mathrm{CO}$ $(\mathrm{CO} 0)$ is $4.52 \pm 0.497 \mathrm{~L} / \mathrm{min}$, mean ETCO2 (ET0) is $32.4 \pm 1.9 \mathrm{mmHg}$, mean MAP (MAP0) is $89.71 \pm 10.606 \mathrm{mmHg}$, and mean HR is 93.13 $\pm 11.708 \mathrm{bpm}$. From examination during PLR, mean $\mathrm{CO}(\mathrm{CO} 1)$ is $4.83 \pm 0.417 \mathrm{~L} / \mathrm{min}$, mean ETCO2 (ET1) is $33.87 \pm 2.097 \mathrm{mmHg}$, mean MAP(MAP1) is $90.27 \pm 8.859 \mathrm{mmHg}$, and mean HR (HR1) is $94.33 \pm 10.512 \mathrm{bpm}$. Nine (30\%) of the subjects are fluid responder, fulfilled the definition of fluid responsive (increase in $\mathrm{CO}$ during PLR more than or equal to $10 \%$ ). Paired sample t-test to compare parameter value before and during PLR maneuver shows significant difference only for ETCO2 $(p=<.001)$ and CO $(p=<.001)$ pairs in all subjects, fluid responder group, and non-fluid responder group (Table 2).

Subject then analyzed according to their PEEP group, low (0-5 $\left.\mathrm{cmH}_{2} \mathrm{O}\right)$, moderate (6$\left.10 \mathrm{cmH}_{2} \mathrm{O}\right)$, and high $\left(>10 \mathrm{cmH}_{2} \mathrm{O}\right)$ with the same two $\Delta \mathrm{EtCO}_{2}$ cut off value by chi-square test (Table 4). The result is in subject group of low and moderate PEEP, $\triangle \mathrm{EtCO}_{2}$ value with cut off of $5 \%$ and $1 \mathrm{mmHg}$ were associated with fluid responsiveness, with $\mathrm{p}$ value of 0.028 and 0.013 , consecutively. In high PEEP group, $\Delta \mathrm{EtCO}_{2}$ value with cut off of $5 \%$ and $1 \mathrm{mmHg}$ was not associated with fluid responsiveness ( $p$ $=0.333$ ).

In the high PEEP group, we performed paired sample t-test to know why $\triangle \mathrm{EtCO}_{2}$ value is not associated with fluid responsiveness (Table 5).
From the analysis of $\mathrm{EtCO}_{2}$ parameter before PLR (ET0) to $\mathrm{EtCO}_{2}$ during PLR (ET1) and CO before PLR (CO0) to CO during PLR (CO1), we found there is no significant change in endtidal carbon dioxide and cardiac output before to during PLR.

\section{DISCUSSION}

This study aims to represent the population of critically ill patients in the emergency room. Most of the subjects in this study are male, like two other studies about intubation in emergency rooms in Hongkong and Singapore (Tam \& Lau, 2001; Wong, Fong, \& Ho, 2004). The median age of subjects in this study is 51.5 years. Three other studies about intubation in the emergency room in Asian hospitals get lower median age (Fathil et al., 2010; Tam \& Lau, 2001; Wong et al., 2004).

We found no difference between static parameters (HR and MAP) before and during PLR for fluid responders and nonfluid responders. We also found no difference between static parameters between both groups. Several studies have found that static parameters couldn't be used to predict fluid responsiveness (Boulain et al., 2002; Caille et al., 2008; Marik \& Cavallazzi, 2013). Both $\mathrm{EtCO}_{2}$ and $\mathrm{CO}$ shows a significant increase before and during PLR for fluid responder and non-fluid responder. There is a difference though that the increase is more substantial in

Table 5. Paired sample t-test in high PEEP group to compare EtCO2 and Cardiac output before to during PLR.

\begin{tabular}{cccc}
\hline Parameter & Timing & Mean \pm SD & p \\
\hline $\mathrm{CO}(\mathrm{L} / \mathrm{menit})$ & Before PLR & $4.19 \pm 0.208$ & \\
& During PLR & $4.42 \pm 0.180$ & 0.161 \\
& Before PLR & $31.67 \pm 3.055$ & \\
$\mathrm{EtCO}_{2}(\mathrm{mmHg})$ & During PLR & $33.0 \pm 3.606$ & 0.057 \\
& &
\end{tabular}

\# Paired sample t-test with significant $\mathrm{p}$ value $<0.05$ 


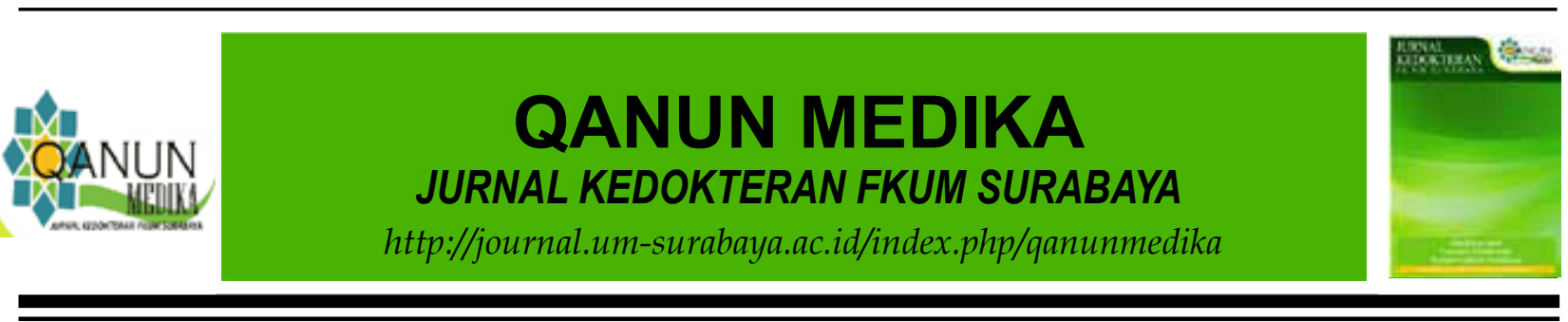

the fluid responder group. Previous studies showed that $\triangle \mathrm{EtCO}_{2}$ strongly correlated with change in CO (Basappanavar et al., 2018; Nassar \& Schmidt, 2016).

Several previous studies used two different $\triangle \mathrm{EtCO}_{2}$ cut off value to identify fluid responder with PLR maneuver: $>5 \%$ (Monnet et al., 2013; Xiao-Ting et al., 2015) and $>1 \mathrm{mmHg}$ (Lakhal et al., 2017) with different sensitivity and specificity. Our study compared both cut-off values and found no difference with a sensitivity of $100 \%$ and specificity of $81 \%$.

Our study found that $\Delta \mathrm{EtCO}_{2}$ is only associated with fluid responsiveness status in low and moderate PEEP groups. In the high PEEP group $(>10 \mathrm{cmH} 2 \mathrm{O})$, there is no association between $\Delta \mathrm{EtCO}_{2}$ value and fluid responsiveness status, both with cut-off values of $5 \%$ and 1 $\mathrm{mmHg}$. Other research has studied the effect of high PEEP on other predictors of fluid responsiveness. A study that compared several predictors of fluid responsiveness in shock patient with ARDS (high PEEP and PIP) and non-ARDS, found that the accuracy of PPV to predict fluid responsiveness in ARDS patient decreased, but both PLR and end-expiratory occlusion test with pulse contour cardiac index as monitor still has good performance (Monnet et al., 2012). Another study in postoperative ICU patients found that SVV threshold value to identify fluid responsiveness increased if PEEP value increased to $10 \mathrm{cmH} 2 \mathrm{O}$ (Kang et al., 2014).

The effect of high PEEP level in disassociation of $\triangle \mathrm{EtCO}_{2}$ with fluid responsiveness that uses PLR can be explained according to PEEP relationship with intrathoracic pressure. PEEP in mechanically ventilated patients increased intrathoracic pressure, followed by an increase in RAP that can be seen from an increase in CVP (Luecke \& Pelosi, 2005). Another study in Iran found that CVP increased for every increase in PEEP, with higher CVP increase happen in lower PEEP baseline (Shojaee et al., 2017).

Guyton predicted that an increase in intrathoracic pressure results in the shifting of the heart function curve to the right along the RAP axis, which was later proved, and this effect was found to be more significant on high PEEP (Bressack \& Raffin, 1987; Marini, Culver, \& Butler, 1981). Researches on pig hearts found that the same bolus volume has less effect in increasing CVP, RAP, and $\mathrm{CO}$ on the pig with higher PEEP (Berglund, Haldén, \& Jakobson, 1994; Renner et al., 2008). We hypothesize that the heart function curve shifting then changes heart response to fluid administration, so fluid bolus with the same volume result in lower RAP and CO increase. This results in high PEEP that actually in lower PEEP would be a fluid responder. The PLR maneuver didn't result in an increase in $\mathrm{CO}$ that is significant enough to fulfill the fluid responsive definition. This is proved in Table 5, where both the value of EtCO2 and CO during PLR doesn't increase significantly. This study has a limitation that we could not exclude the possibility that high PEEP also affects the blood volume from the inferior extremity that comes back to systemic circulation during PLR maneuver through PEEP effect on intraabdominal pressure.

\section{CONCLUSION}

$\Delta \mathrm{EtCO}_{2}$ as cardiac output surrogate can be used to identify fluid responsiveness in mechanically ventilated with low and moderate PEEP level who were undergoing PLR maneuver, with cutoff value of $5 \%$ or $1 \mathrm{mmHg}$, but it lost its ability in a patient with high PEEP $(>10 \mathrm{cmH} 2 \mathrm{O})$. We suggest that future studies should compare with other cardiac output monitoring, such as arterial pulse contour analysis, and do the diagnostic testing to rate the sensitivity and specificity of these tests before its gold standard. 


\section{REFERENCES}

Basappanavar, V. S., Vadlamani, S., Joshi, S. S., BS, M., Singh, N. G., \& Pandey, G. (2018). EC ANAESTHESIA Research Article End-Tidal Carbon Dioxide as Marker of Cardiac Index after Weaning from Cardiopulmonary Bypass. EC Anaesthesia, 7(4), 225-231.

Berglund, J. E., Haldén, E., \& Jakobson, S. (1994). The effect of peep-ventilation on cardiac function in closed chest pigs. Upsala Journal of Medical Sciences, 99(2), 167-178. https://doi. org/10.3109/03009739409179361

Boulain, T., Achard, J. M., Teboul, J. L., Richard, C., Perrotin, D., \& Ginies, G. (2002). Changes in BP induced by passive leg raising predict response to fluid loading in critically ill patients. Chest, 121(4), 1245-1252. https://doi.org/10.1378/ chest.121.4.1245

Bressack, M. A., \& Raffin, T. A. (1987). Importance of Venous Return, Venous Resistance, and Mean Circulatory Pressure in the Physiology and Management of Shock. CHEST, 92(5), 906-912. https:// doi.org/10.1378/chest.92.5.906

Caille, V., Jabot, J., Belliard, G., Charron, C., Jardin, F., \& Vieillard-Baron, A. (2008). Hemodynamic effects of passive leg raising: An echocardiographic study in patients with shock. Intensive Care Medicine, 34(7), 1239-1245. https://doi. org/10.1007/s00134-008-1067-y

Fathil, S. M., Mahdi, S. N. M., Che'Man, Z., Hassan, A., Ahmad, Z., \& Ismail, A. K. (2010). A prospective study of tracheal intubation in an academic emergency department in Malaysia. International Journal of Emergency Medicine, 3(4), 233-237. https://doi.org/10.1007/s12245010-0201-0
Grübler Martin, R., Olivier, W., David, B., \& Stefan, B. (2017). Basic concepts of heart-lung interactions during mechanical ventilation. Swiss Medical Weekly, 147(37-38), 1-14. https://doi. org/10.4414/smw.2017.14491

Jin, X., Povoas, H., Pernat, A., Xie, J., Weil, M. H., Tang, W., \& Bisera, J. (2000). End-tidal carbon dioxide as a noninvasive indicator of cardiac index during circulatory shock. Critical Care Medicine, 28(7), 24152419. https://doi.org/10.1097/00003246200007000-00037

Kang, W. S., Kim, S. H., Kim, S. Y., Oh, C. S., Lee, S. A., \& Kim, J. S. (2014). The influence of positive end-expiratory pressure on stroke volume variation in patients undergoing cardiac surgery: An observational study. Journal of Thoracic and Cardiovascular Surgery, 148(6), 3139-3145. https://doi.org/10.1016/j. jtcvs.2014.07.103

Lakhal, K., Nay, M. A., Kamel, T., LortatJacob, B., Ehrmann, S., Rozec, B., \& Boulain, T. (2017). Change in endtidal carbon dioxide outperforms other surrogates for change in cardiac output during fluid challenge. British Journal of Anaesthesia, 118(3), 355-362. https:// doi.org/10.1093/bja/aew478

Luecke, T., \& Pelosi, P. (2005). Clinical review: Positive end-expiratory pressure and cardiac output. Critical Care, 9(6), 607-621. https://doi.org/10.1186/cc3877

Marik, P. E., \& Cavallazzi, R. (2013). Does the central venous pressure predict fluid responsiveness? An updated metaanalysis and a plea for some common sense. Critical Care Medicine, 41(7), 1774-1781. https://doi.org/10.1097/ CCM.0b013e31828a25fd 

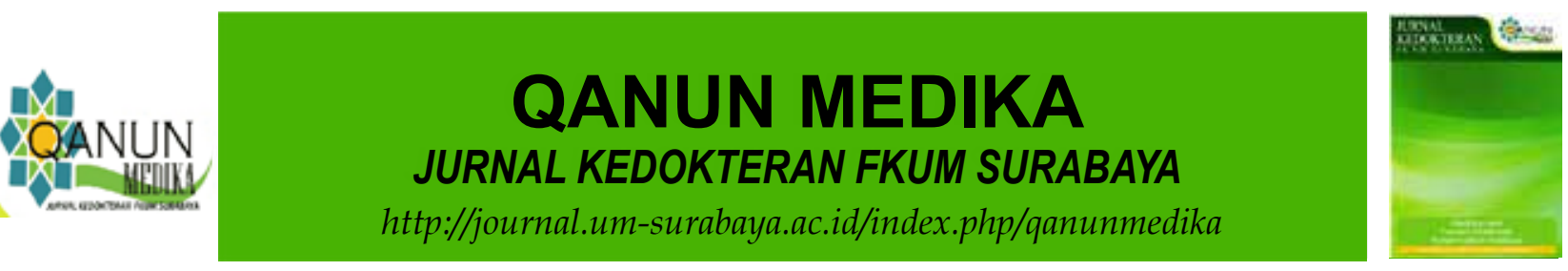

Marik, P. E., Cavallazzi, R., Vasu, T., \& Hirani, A. (2009). Dynamic changes in arterial waveform derived variables and fluid responsiveness in mechanically ventilated patients: A systematic review of the literature. Critical Care Medicine, 37(9), 2642-2647. https://doi. org/10.1097/CCM.0b013e3181a590da

Marini, J. J., Culver, B. H., \& Butler, J. (1981). Effect of positive end-expiratory pressure on canine ventricular function curves. $J$ Appl Physiol Respir Environ Exerc Physiol, 51(6), 1367-1374.

Michard, F., Chemla, D., \& Teboul, J. L. (2015). Applicability of pulse pressure variation: How many shades of grey? Critical Care, 19(1), 15-17. https://doi. org/10.1186/s 13054-015-0869-x

Monnet, X., Bataille, A., Magalhaes, E., Barrois, J., Le Corre, M., Gosset, C., ... Teboul, J. L. (2013). End-tidal carbon dioxide is better than arterial pressure for predicting volume responsiveness by the passive leg raising test. Intensive Care Medicine, 39(1), 93-100. https://doi. org/10.1007/s00134-012-2693-y

Monnet, X., Bleibtreu, A., Ferré, A., Dres, M., Gharbi, R., Richard, C., \& Teboul, J. L. (2012). Passive leg-raising and end-expiratory occlusion tests perform better than pulse pressure variation in Patients with low respiratory system compliance. Critical Care Medicine, 40(1), 152-157. https://doi.org/10.1097/ CCM.0b013e31822f08d7

Monnet, X., \& Teboul, J. L. (2015). Passive leg raising: Five rules, not a drop of fluid! Critical Care, 19(1), 18-20. https://doi. org/10.1186/s13054-014-0708-5
Nassar, B. S., \& Schmidt, G. A. (2016). Capnography during critical illness. Chest, 149(2), 576-585. https://doi.org/10.1378/ chest.15-1369

Ortega, R., Connor, C., Kim, S., Djang, R., \& Patel, K. (2012). Monitoring ventilation with capnography. New England Journal of Medicine, 367(19), e27(1). https://doi. org/10.1056/NEJMvcm1105237

Pantazopoulos, C., Xanthos, T., Pantazopoulos, I., Papalois, A., Kouskouni, E., \& Iacovidou, N. (2015). A Review of Carbon Dioxide Monitoring During Adult Cardiopulmonary Resuscitation. Heart Lung and Circulation, 24(11), 1053-1061. https://doi.org/10.1016/j.hlc.2015.05.013

Renner, J., Gruenewald, M., Meybohm, P., Hedderich, J., Steinfath, M., Scholz, J., \& Bein, B. (2008). Effect of elevated PEEP on dynamic variables of fluid responsiveness in a pediatric animal model. Paediatric Anaesthesia, 18(12), 1170-1177. https://doi.org/10.1111/ j.1460-9592.2008.02770.x

Schuller, D., \& Schuster, D. P. (2006). Fluidmanagement strategies in acute lung injury [5]. New England Journal of Medicine, 355(11), 1175. https://doi.org/10.1056/ NEJMc061857

Shojaee, M., Sabzghabaei, A., Alimohammadi, H., Derakhshanfar, H., Amini, A., \& Esmailzadeh, B. (2017). Effect of Positive End-Expiratory Pressure on Central Venous Pressure in Patients under Mechanical Ventilation. Emergency (Tehran, Iran), 5(1), e1. https://doi. org/10.22037/emergency.v5i1.11245 


\section{QANUN MEDIKA \\ JURNAL KEDOKTERAN FKUM SURABAYA \\ http://journal.um-surabaya.ac.id/index.php/qanunmedika}

Tam, A. Y. B., \& Lau, F. L. (2001). A prospective study of tracheal intubation in an emergency department in Hong Kong. European Journal of Emergency Medicine, 8(4), 305-310. https://doi. org/10.1097/00063110-200112000-00011

Weil, M. H., Bisera, J., Trevino, R. P., \& Rackow, E. C. (1985). Cardiac output and end-tidal carbon dioxide. Critical Care Medicine, Vol. 13, hal. 907-909. https:// doi.org/10.1097/00003246-19851100000011

Wong, E., Fong, Y. T., \& Ho, K. K. (2004). Emergency airway management Experience of a tertiary hospital in south-east Asia. Resuscitation, 61(3), 349-355. https://doi.org/10.1016/j. resuscitation.2004.01.011
Xiao-Ting, W., Hua, Z., Da-Wei, L., HongMin, Z., Huai-Wu, H., Yun, L., \& WenZhao, C. (2015). Changes in end-tidal $\mathrm{CO} 2$ could predict fluid responsiveness in the passive leg raising test but not in the mini-fluid challenge test: A prospective and observational study. Journal of Critical Care, 30(5), 1061-1066. https:// doi.org/10.1016/j.jcrc.2015.05.019

Zochios, V., \& Wilkinson, J. (2011). Assessment of intravascular fluid status and fluid responsiveness during mechanical ventilation in surgical and intensive care patients. Journal of the Intensive Care Society, 12(4), 295-300. https://doi. org/10.1177/175114371101200410 